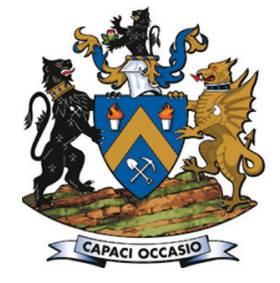

Affiliation:

${ }^{1}$ Mining Engineering Department, University of Pretoria.

Correspondence to: E.P. Preis

R.C.W. Webber-Youngman

\section{Email:}

eugenepreis@gmail.com ronny.webber@up.ac.za

\section{Dates:}

Received: 10 Sep. 2018

Accepted: 13 Jan. 2021

Published: January 2021

\section{How to cite:}

Preis, E.P. and

Webber-Youngman, R.C.W. 2021

Identification of cost factors

relating to mining incidents.

Journal of the Southern African

Institute of Mining and Metallurgy, vol. 121 , no. 1 , pp. 39-46.

\section{DOI ID:}

http://dx.doi.org/10.17159/24119717/16/484/2021

\title{
Identification of cost factors relating to mining incidents
}

\author{
E.P. Preis ${ }^{1}$ and R.C.W.Webber-Youngman ${ }^{1}$
}

\begin{abstract}
Synopsis
The real cost of any mining incident has, empirically, proven to be estimation-driven, rather than factdriven. One of the main reasons for this lies with the complexity of the cost composition of any given mining incident. Incident costs comprise both direct and indirect cost factors, and in many cases the costs associated with these factors are incurred during different time periods following the incident. In this paper we aim to identify the various cost factors arising from mining incidents, provide a thorough understanding of all the potential cost factors identified, and draw general conclusions on the knowledge obtained.

Furthermore, recommendations are made on how mining companies could use the results, in order to assist them in calculating the costs of mining incidents. The paper also provides suggestions for further research, with the emphasis on the most significant immeasurable cost factors, namely the costs of implementing job accommodations following an incident, the harm to company reputation, and the decreased productivity due to low worker morale/psychological factors following an incident.

If mining companies are aware of and understand which factors could contribute to the cost of any given incident, future planning and incident cost estimations could be easier. It should, however, be noted that although this study provides a comprehensive list of cost factors (and detailed explanations), other unknown cost factors relating to mine incidents could prevail in extreme cases.
\end{abstract}

\section{Keywords}

direct costs, indirect costs, mining incidents.

\section{Introduction}

Zero harm is a vision that is fully subscribed to by all South African mines. The main objective of the vision is to eliminate injuries and fatalities. Apart from the effects related to injuries and fatalities, mining incidents involve considerable costs for mines. The various factors that influence the costs of an incident are not always that obvious, and this can have major downstream implications (e.g. an incident may result in future opportunity losses due to the harm caused to a company's reputation). The purpose of this investigation was to identify all the potential cost factors associated with mine incidents and quantify the understanding and significance related to incidents. The difference between, and impact of, quantifiable and non-quantifiable factors was also addressed.

\section{Background}

To ensure a clear understanding of the cost of incidents and related factors, it is necessary to firstly provide definitions for the primary components of incident costs. These terms/phrases are used throughout this study. The total cost associated with an incident can be broadly classed into three main categories: costs to employees, costs to society as a whole, and costs to the employer (Table I).

The objective of this study was to focus solely on identifying the cost factors relating to mine incidents, from a 'cost to employer' perspective. It was, however, necessary to provide definitions for the other incident cost categories to prevent any misunderstanding or confusion.

The actual cost of an incident is a concept that seems simple to calculate and understand. Incident costs are split into direct (visible) costs and indirect (hidden) costs. The relationship between direct and indirect costs of an incident can be compared to an iceberg. The entirety of the iceberg represents all incident costs - with the submerged part representing the indirect costs and the visible part representing the direct costs (Figure 1).

The iceberg analogy suggests that the indirect costs of an incident are much more substantial than the direct costs. To quantify the relationship between direct and indirect costs, a ratio of direct to indirect costs can be expressed. However, whether this ratio is in fact something that can or should be quantified and benchmarked is unclear. The literature suggests that ratios vary greatly, from 1:1 to 1:36 (Table II). 


\section{Identification of cost factors relating to mining incidents}

\section{Table 1}

\section{Broad incident cost categories}

\begin{tabular}{|l|l|}
\hline Category & Definition \\
\hline Costs to employees & $\begin{array}{l}\text { All incident-related costs for which the affected employee is responsible for (or in the case of a deceased employee, their family will assume this } r \\
\text { esponsibility). The costs to employee includes the loss of future earnings, the cost of human suffering, as well as other miscellaneous expenses } \\
(e . g . \text { an injured employee not at work has a higher cost of living than if at work). Costs to Employee do not affect the cost to employer, although the } \\
\text { burden of some costs due to an incident is shared between the two parties. }\end{array}$ \\
\hline Costs to society & $\begin{array}{l}\text { All incident-related costs for which society as a whole is responsible for, whether directly or indirectly. An example of this is the worker's compensation fund, } \\
\text { the burden of which falls upon the widespread economy of South Africa. In the case of an injured/deceased working individual, the economic impact of this } \\
\text { individual not being able to contribute towards the country's economy falls upon the country as a whole (society). }\end{array}$ \\
\hline Costs to employer & $\begin{array}{l}\text { All incident-related costs for which the employer is responsible. These can be costs that are direct or indirect, costs which are only felt some time after } \\
\text { incident occurrence, and costs that take on the form of losses relating to the company (real losses or opportunity losses). The approach to determining } \\
\text { which costs fall within this category is to ask the question - 'Would this cost/loss have been incurred if the incident had not happened?' If the answer is no, } \\
\text { then it is a cost to the employer due to incident occurrence. }\end{array}$
\end{tabular}

\section{Table II}

Different ratios of direct vs. indirect costs of incidents

\begin{tabular}{|c|c|c|c|}
\hline & Ratio & Comments & Source \\
\hline \multirow{2}{*}{$\begin{array}{l}\text { Average } \\
\text { Range }\end{array}$} & $1: 4$ & \multirow{2}{*}{ Based on historical cost data of incidents. } & \multirow{2}{*}{ Manuele, 2011} \\
\hline & $1: 2-1: 20$ & & \\
\hline Average & $1: 2.12$ & \multirow{2}{*}{ As perceived by 231 financial decision-makers. } & \multirow{2}{*}{ Huang et al., 2009} \\
\hline Range & 1:0-1:11 & & \\
\hline \multirow[t]{2}{*}{ Average } & $1: 4.5$ & For incidents with a direct cost of up to US $\$ 2999$. & \multirow{2}{*}{ United States Department of Labour, 2011} \\
\hline & $1: 1$ & For incidents with a direct cost of more than US\$10 000. & \\
\hline Average & $1: 10$ & $\begin{array}{l}\text { Average ratio of insured to uninsured costs, perceived by the British Health } \\
\& \text { Safety Executive (HSE) as direct and indirect costs. }\end{array}$ & \multirow[t]{2}{*}{ British Health \& Safety Executive, 1998} \\
\hline Range & $1: 2-1: 36$ & Range of historical insured to uninsured cost ratios (direct vs. indirect). & \\
\hline
\end{tabular}

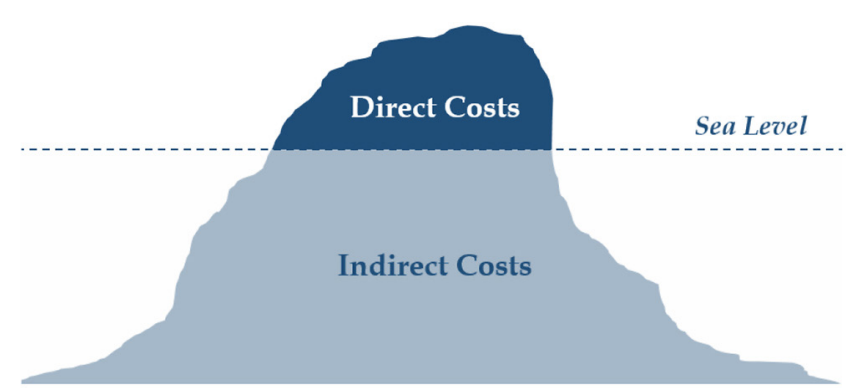

Figure 1-Incident cost iceberg analogy

The great variance in ratios shows that estimating the costs of incidents involves a large degree of uncertainty. In terms of this study, this variance showed that further investigation was required into the actual factors that contribute to the total cost of an incident. The identification and understanding of all cost factors relating to mine incidents acts as the starting point in understanding (and more accurately quantifying) the cost of mining incidents. This could assist in classifying incidents by type, and estimating direct $v s$. indirect ratios for each class of incident much more accurately.

By identifying and understanding the potential cost contributing factors, it would be possible to highlight the most significant financial consequences of mine incidents. This, in turn, would enable the separation or highlighting of specific individual factors, and then determining their effect on the total cost of incidents, which in turn will quantify their significance.

\section{Cost factors relating to mining incidents}

Cost factors relating to mining incidents were identified through a literature search. The approach focused firstly on any previous work done on incident cost factors in the workplace, irrespective of the type of workplace, and then narrowing down to work on the cost factors of mining incidents. The cost factors identified were all found to be potentially applicable to the mining industry, albeit with varying probabilities of occurrence.

A total of 34 main cost factors relating to mine incidents were identified, along with numerous sub-factors. Out of the 34 factors identified, eight were classified as direct cost factors and 26 as indirect factors.

\section{Direct cost factors}

The eight direct cost factors relating to mining incidents, as well as any relevant sub-factors, are explained under their respective headings.

\section{Lost planned reserves}

Blumenstein et al. (2011) identified lost reserves as a potential cost-contributing factor in mining incidents. However, their description was found to be broad, and thus the cost item was adopted rather as 'Lost planned reserves'. A lost planned reserve refers to the loss of future planned reserves due to an incident, resulting in mineable future reserves being rendered unmineable. This only applies to non-active work sites - if production is lost from an active workplace, the cost item 'Lost planned production and recovery thereof' applies. 


\section{Identification of cost factors relating to mining incidents}

The loss of reserves should be seen as a lost asset, the amount of loss depending on the size of the lost reserve and the specific reserve quality (e.g. in the case of coal, calorific value, ash content, volatiles content, etc.).

\section{Lost sales}

Lost sales refers to the value of sales lost due to an accident (Blumenstein et al., 2011). Lost sales will be applicable only when a mine is unable to deliver product to a customer, both on the contractually agreed-upon date and the agreed amount. Lost sales will apply only if the mine in question does not stockpile, else this item should be seen as a loss of asset. The assumption is that if the mine stockpiles, there is no chance of lost sales being incurred. There will, however, be a loss of asset due to the stockpile size decreasing.

\section{Property damage, repair and replacement}

Lebeau, Duguay, and Boucher (2013) identified property damage as a common contributor to incident costs. Property damage, repair and replacement refers to the cost of replacing or repairing any type of equipment damaged due to an incident. This item also includes all costs pertaining to temporary measures put in place, such as hiring equipment until permanent equipment has been purchased.

It must be noted that property damage requiring repairs or replacement should be analysed carefully, as numerous indirect costs can be overlooked. Any wages associated with property damage, repair and replacement should fall under the cost item 'All lost-time salaries', unless the salaries are for external contractors. The potential sub-factors that may arise through damage to property are shown in Table III.

\section{All lost-time salaries}

All lost-time salaries can be defined as the full salary (plus benefits) cost of non-performance of work due to (Lebeau, Duguay, and Boucher, 2013; Blumenstein et al., 2011; Workers Compensation Board of British Columbia, n.d.):

- Injury to employee(s)

> Permanently disabled employee(s)

$>$ Non-productive employees due to incidents prohibiting work from commencing.

The salary cost of a permanently disabled employee due to an incident will be incurred until workers compensation comes into effect. The full cost should be measured from the time of the incident until employer salary responsibilities are relieved by the worker's compensation fund. The salary cost of an employee who suffers a non-disabling injury will be incurred until the employee is declared fit to return to work. This cost should be measured from the time of the incident until the injured employee returns to work. It should be noted that upon returning to work, the employee could temporarily be less productive and incur further costs related to decreased productivity.

The cost of long-term absenteeism includes one component that short-term absenteeism does not incur, and that is the loss of productivity/momentum of the employee. An employee returning to work from an extended leave of absence has to readjust to work conditions. This means that for a certain time period after returning to work, the employee will be less productive than he/ she is normally. The cost of this temporary loss in productivity is included under the cost item 'Lost productivity'. The salary cost of an employee rendered inactive due to an incident will be incurred until work can resume.

\section{Lost planned production and recovery thereof}

This item refers to the loss of production from an active work site due to an incident. It must be noted that the cost of lost planned production will be incurred only if the lost product can never be retrieved. The loss of planned production should be seen as a lost revenue-generating opportunity, and not necessarily a cost. The only real cost for this item is the additional operating expense incurred during recovery efforts. Nevertheless, both the opportunity loss and recovery cost should be included as a cost due to the incident.

\section{Work site recovery}

Work site recovery includes the costs incurred due to recovery efforts in an affected work site. If the recovery of the work site is performed by idle workers, then it should not be seen as a cost item, unless the idle workers incur overtime (the assumption being that the idle workers would have been paid regardless). Work site recovery may include reconstruction of access or moving of material or equipment (Blumenstein et al., 2011).

If the work is performed by a contractor, then the contractor wages will be accounted for. Additional consumables due to recovery efforts also need to be accounted for (such as fuel, explosives, etc.). This item excludes the clean-up of a work site due to property damage, which is included under Equipment repair and replacement.

\section{Penalties and SIMRAC levies}

This cost item refers to the penalties/levies payable to the South African Safety in Mines Research Advisory Committee (SIMRAC). The South African Mines Reportable Accidents Statistical System (SAMRASS) codebook provides further information on the lost-days penalties payable for specific injuries. As an example, the safety levy component of a fatality on a mine will result in a

Table III

Potential sub-factors: Property damage, repair and replacement

\begin{tabular}{|c|c|}
\hline Sub-factor & Definition/example \\
\hline Removal of damaged/written-off equipment from work site & $\begin{array}{l}\text { The cost of towing services to remove the equipment from the site, whether it is taken to a scrapyard, or to the } \\
\text { on-site workshops. }\end{array}$ \\
\hline Clean-up of spillage caused by damaged equipment & The cost of clean-up of the site following the property damage incident (eg. oil spillage from hydraulics of equipment). \\
\hline $\begin{array}{l}\text { Cost of repair work and parts } \\
\text { (Workers Compensation Board of British Columbia, n.d.) }\end{array}$ & The cost of repairing the damaged equipment, as well as the cost of ordering, receiving, and installing new parts. \\
\hline Cost of replacement equipment (LaBelle, 2000) & $\begin{array}{l}\text { The cost of replacement equipment if equipment repair is not financially viable. The depreciated book-value of the } \\
\text { written-off equipment should be used. }\end{array}$ \\
\hline Cost of renting interim equipment & $\begin{array}{l}\text { The cost of renting equipment while the damaged equipment is being repaired, or for the waiting period associated } \\
\text { with the ordering of new equipment. }\end{array}$ \\
\hline
\end{tabular}




\section{Identification of cost factors relating to mining incidents}

total of 6000 lost days' penalty. Using the 2009-2012 levy cycle rate of R9.77 per lost day, the safety levy component per fatality would be R58 620 (during 2009-2012).

\section{Incident response operations}

An incident response operation includes all expenses related to direct incident response. This can include items such as mine rescue, fire-fighting, ambulance services, first aid, etc. (Blumenstein et al., 2011). The items comprising the incident response operations include materials consumed as well as services costs (measure with time lapsed).

If the mine made use of internal mine rescue/incident response which did not result in overtime, the cost should not be added. The assumption is that if an incident-related task falls under the specific person's job description and does not result in overtime, the task should not be seen as a cost contributor. Whether or not the incident occurred, the task performer would have been remunerated by the same amount. The potential subfactors that may arise through incident response operations can be seen in Table IV.

\section{Indirect cost factors}

The 26 indirect cost factors relating to mining incidents, as well as any relevant sub-factors, are explained under their respective headings.

\section{Harm to company reputation}

Harm to company reputation, or reputational loss (Gagne, 2011), refers to the cost of harm caused to a company's reputation following an incident. This can be incurred in several forms, such as:

> Cancelled/lost orders (Royal Borough of Kensington and Chelsea, 2002): Cancelled/lost orders can be seen as future orders lost from an existing customer, or as lost opportunities. An incident may lead to a potential customer deciding to not make use of the company services in the future. The company may also never know that they lost business opportunities due to the incident. Damage to a company's reputation might result in customers turning to competitor suppliers (Malaysian Department of Occupational Health and Safety, n.d.).

> Possible tensions in labour relations: Employees may decide to strike due to their feeling unsafe in the workplace following an incident. In this case, harm will be caused to the company reputation, as well as production losses.

> Recruitment problems (Lebeau, Duguay, and Boucher, 2013): A company with a damaged reputation could struggle to recruit new employees (people do not want to work for a company with a poor reputations). If the company is unable to employ new workers, productivity levels will drop.
- Department of Mineral Resources (DMR) impact: Harm caused to a mining company's reputation could lead to the withholding of rights from the DMR for future/expansion projects.

There are numerous factors involved in harm to company reputation. The company's market capitalization could be affected; and potential future investment from external investors might not be realized. These factors will manifest over time, and their financial effects might be realized only long after the incident has occurred.

The ACE Group (2013) conducted a study on risk management for European companies. The study focused on the potential financial impact felt due to a tainted company reputation.A questionnaire was sent to more than 100 medium to large-sized companies. One of the questions was aimed at sdetermining which potential impacts of reputational risk would cause the greatest concern to a business (Figure 2).

Figure 2 shows that damage to existing customer relationships, followed by a loss of earnings and fall in company share price, were the three biggest concerns in terms of the impacts of harm to a company's reputation. These concerns all apply to the mining industry, albeit in derivative forms.

\section{Decreased productivity}

Blumenstein et al. (2011) define the cost of decreased productivity as the cost of lower productivity due to using inexperienced replacement workers. An employee returning to work after recovering from an injury could be less efficient and/ or less productive than before the injury. This could last for a finite time period, or until the employee reaches retirement. Assuming that the employee returns to the same specific job, a reduced efficiency will have a considerable cost impact on the company. This could be due to physical constraints (recovering from the injury) or to psychological aspects (e.g. increased risk averseness, anxiety, and stress).
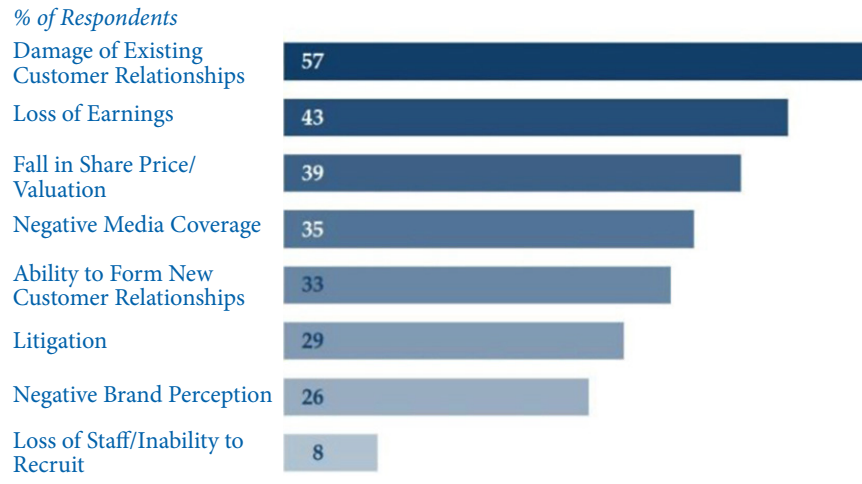

Figure 2-Potential impacts of reputational risk that cause the greatest concern to a business (ACE Group, 2013)

Table IV

\section{Potential sub-factors: Incident response operations}

\begin{tabular}{|l|l|}
\hline Sub-factor & Definition/example \\
\hline Ambulance services (LaBelle, 2000; Lebeau, Duguay, and Boucher, 2013) & Costs as per service provider. For transport (if required) from incident site to treatment facility/hospital. \\
\hline Time to provide first-aid (Avma Plit, 2008; Gagne, 2011) & $\begin{array}{l}\text { Salary cost of first-aid worker attending to injured employee and of persons arranging ambulance } \\
\text { services and transportation. }\end{array}$ \\
\hline $\begin{array}{l}\text { Time for transportation following incident } \\
\text { (Workers Compensation Board of British Columbia, n.d.) }\end{array}$ & $\begin{array}{l}\text { Salary cost of person taking injured employee to hospital (if not ambulance services); salary cost of } \\
\text { waiting for transportation; salary cost of person remaining with injured employee in hospital. }\end{array}$ \\
\hline Police/firefighting services (Blumenstein et al., 2011) & The cost incurred due to the call-out of police or fire-fighting services \\
\hline
\end{tabular}




\section{Identification of cost factors relating to mining incidents}

In this case the company will have to spend the same amount on the employee's wages (input) for a reduced output. To maintain the same level of productivity as before the incident, the company will have to spend more money elsewhere to compensate for the lost efficiency of the temporarily 'handicapped' employee. In mining, this potential reduction in efficiency will most likely apply to physical labourers.

The removal of a worker from a familiar workplace will decrease in productivity in the area the employee was removed from as well as in the relocation area. However, this will not always be the case - the effect may be the opposite in some cases (Workers Compensation Board of British Columbia, n.d.).

\section{Impact of decreased worker morale}

An incident could lead to a decrease in worker morale (AVMA PLIT, 2008; Gagne, 2011), and the potential impacts on productivity following an incident can be numerous. Lower motivation to work, workforce morale decreasing, and an increased rate of absenteeism by fellow workers may be felt following an incident (Malaysian Department of Occupational Safety and Health, n.d.). In theory, all these factors can be measured by comparing historical production rates and rates of absenteeism before and after the incident. This would, however, be possible only if all other factors remained equal (ceteris paribus), which in practice is impossible. Studies have been conducted in order to understand the link between the level of safety in the workplace and employee morale (Figure 3).

A low level of employee morale could lead to a decrease in productivity, which will inevitably result in financial loss. A workplace that does not comply with safety standards could cause poor morale due to the psychological impact on employees (employees working in an unsafe environment are more likely to be demoralized and less productive).

\section{Processing plant stoppage costs}

Processing plant stoppage costs refers to the cost/loss incurred due to any form of plant stoppage caused by an incident, including both mining incidents and processing plant incidents. It must, however, be noted that this cost factor is unlikely to be incurred unless an incident causes damage to plant-related equipment, or it is deemed unsafe to continue running the plant after an incident.

\section{Job accommodations}

Job accommodation refers to the long-term cost of a loss in production time due to an adjustment to or implementation of new safety procedures/practices. This cost item comprises two components, namely the cost of implementing modifications to equipment, procedures, or standards and the long-term cost impact of the modifications.

If an incident necessitates the redesign of a piece of equipment, methodology, or standard operating procedure, the direct cost of the redesign must be included. The after-effects of the redesign must also be considered (indirect cost of job accommodations). This will most likely take the form of a decrease in productivity, which could last for a finite or indefinite time period. This being said, a job accommodation will not always result in decreased productivity, and could potentially have a positive impact in the long run (by improving efficiencies). The redesign could in actual fact lead to an improvement to the system and a consequent improvement in productivity. Thus, job accommodations could be either positive or negative in terms of the total cost estimation.

Consider a scenario where an incident occurs on a mine. This type of incident has never occurred before, and exposes a flaw in one of the company's safety procedures. This flaw is corrected by adapting the specific safety procedure in question, which leads to an extra 15 minutes in the pre-shift safety meeting. This results in a shift losing 15 minutes of production time. The adjusted safety procedure is implemented for the rest of the life of mine. Thus, the mine is now losing production time every day. The cost of this continuous lost production time will not be minimal - however, quantifying this cost is nigh-on impossible. The potential sub-factors that may arise through employee replacement and training can be seen in Table V.

\section{Damage to the environment}

This cost item refers to penalties payable due to environmental contamination following an incident. It also includes the cost of restoring the environment to its natural, pre-incident state. It must be noted that this cost item can comprise of several subfactors, depending on the nature of the mine and the incident.

\section{Product replacement}

An incident could lead to product needing to be replaced in order to meet contractual obligations. Product replacement refers to the cost incurred if an incident results in a client not receiving product that has been paid for, and which has to be replaced by the mine at their own cost (Blumenstein et al., 2011). This item

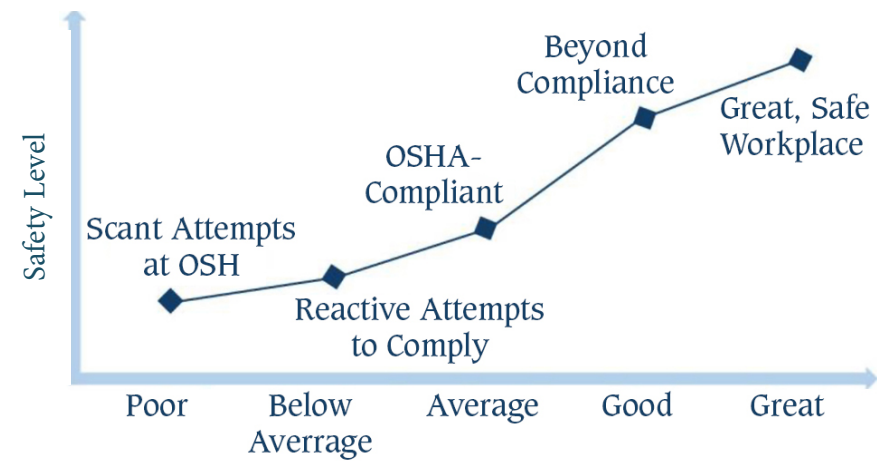

Figure 3-Hypothetical relationship between safety level and employee morale (Behm, 2009)

Table $V$

Potential sub-factors: Job accommodations

\begin{tabular}{|l|l|}
\hline Sub-factor & Definition/example \\
\hline Equipment/tool/personal protective equipment (PPE) redesign (LaBelle, 2000) & $\begin{array}{l}\text { The cost/gain from redesigning a specific tool or piece of equipment, following an incident. } \\
\text { For example, installation of hand-guard on the conveyor belt operating switch. }\end{array}$ \\
\hline Process redesign & Redesign/redirection of process flow. \\
\hline Standard operating procedure redesign (methodology redesign) & $\begin{array}{l}\text { Cost of changes to COP/SOP. Essentially changes to the standard methodology used to } \\
\text { complete a specific task. }\end{array}$ \\
\hline
\end{tabular}




\section{Identification of cost factors relating to mining incidents}

will be incurred only if the mine does not stockpile and cannot deliver its own product to a specific client. It will be very rare for this cost item to arise due to an incident, but nevertheless it can occur.

\section{Workers compensation premium adjustment}

This refers to the cost of an increased compensation premium, measured over a certain time period. The premiums that mining company has to pay towards the National Workers Compensation Fund, can increase or decrease according to safety performance.

Workers compensation payments are not regarded as a cost-contributing factor for the company. The reason for this is the way that the fund is structured. Each mine pays a timebased premium towards the fund, and this premium is adjusted according to the safety records for that year. Thus, where the workers compensation fund will impact on the cost of incidents is the rise in yearly/monthly premiums payable. This value will be time-sensitive.

\section{Liability paid}

This cost factor refers to the uninsured amount paid in thirdparty claims or non-mine liability claims. Specific insurance agreements with the mine's insurance provider can be consulted, if the company is not self-insured.

\section{Legal fees}

Incidents involving lawsuits and/or liability claims need to account for the fees paid for legal assistance due to the incident. This item will include all legal fees incurred due to an incident, as well as employee lost time. The time that an employee has to sit with a legal team and testify must be accounted for. If, for example, the CEO has to sit with a legal team (and this does not result in overtime) the lost time must not be accounted for as it falls within the CEO's job description.

\section{Insurance premium increase}

An incident that results in an insurance claim could lead to a company's premiums increasing, and this cost needs to be accounted for. The annual premium that a company pays is determined according to an estimate of leave of absence, number of hospitalization days, the severity of the accident, potential lawsuits, and the financial cost of damage to equipment, commodities, and facilities. The premium varies from year to year according to events that occurred in the previous year.

\section{Insurance deductible}

Insurance deductible refers to the amount of a claim payable by the company before compensation takes effect. If the company is not self-insured, the insurance agreement with the insurance provider should be consulted.

\section{Excess claim payments}

An excess claim payment on insurance refers to the amount payable by a company over and above insurance coverage. Specific insurance agreements with the mine's selected insurance provider can be consulted if the company is not self-insured.

\section{Incident investigation time}

Incident investigation time includes the costs associated with the investigation of the incident by inspectors as well as SHEQ mine employees. If mine employees perform investigations, the cost should be included only if it falls outside of their job description or results in overtime. Investigation of incidents is what SHEQ does; their salaries would have been paid regardless of whether or not sthe incident occurred. The potential sub-factors that may arise through uncompensated medical expenses can be seen in Table VI.

\section{Incident-related interviews}

The cost of time spent interviewing employees and witnesses is categorized as the cost of incident-related interviews. The interviewer time should be considered as a cost only if the interview falls outside their job description, results in overtime, or if the interviewer is a contractor. The interviewee cost component should be included only if the interview prevents the employee from performing work. If the interview is performed during idle time, it should not be accounted for (as it has already been accounted for in lost-time salaries). If the interview results in the interviewee incurring overtime, it should be accounted for.

\section{Incident-related meetings and report preparation}

Any incident has to be investigated and a report written up. All meetings pertaining to the incident, as well as report preparation, fall under this cost item. The time spent in meetings and preparing the report should be accounted for only if it resulted in overtime, fell outside the job description of those involved, or if a contractor was brought in.

\section{Employee replacement and training}

This item refers to the cost of hiring and training replacement employees following an incident. This applies to both temporary employees and new full-time employees. The costs in this item would include the time spent interviewing potential replacements, but only if the interview time falls outside the job description of the interviewer or if overtime is incurred. The wages paid to the hired employee during the training period have to be accounted for.

There will be a substantial difference in the total cost incurred for this item if the replacement is an existing employee. The potential sub-factors that may arise through employee replacement and training can be seen in Table VII.

\section{Product damage}

The Malaysian Department of Occupational Safety and Health (n.d.), amongst other types of damage, identified product damage as a potential cost factor. In mining, the product is essentially ore,

Table VI

Potential sub-factors: Incident investigation time

\begin{tabular}{|l|l|}
\hline Sub-factor & Definition/example \\
\hline Ambulance services & Costs as per service provider for transport (if required) from incident site to treatment facility/hospital. \\
\hline Time to provide first-aid & Salary cost of first-aid worker attending to injured employee; salary cost of persons to arrange for ambulance services and transportation. \\
\hline Time for transportation following incident & $\begin{array}{l}\text { Salary cost of person taking injured employee to hospital (if not ambulance services); salary cost of waiting for transportation; salary } \\
\text { cost of person remaining with injured employee in hospital. }\end{array}$ \\
\hline
\end{tabular}




\section{Identification of cost factors relating to mining incidents}

and it seems almost impossible for ore to be 'damaged' (although it can occur in extreme cases). Consider an example where a gold processing plant experiences a drop in recovery due to contaminated ore as a result of a hydraulic oil spill from damaged equipment. The reduction in plant recovery is an indirect cost of product damage.

\section{Claims paperwork time}

If an incident results in insurance claims being filed, the cost of time spent preparing and filing claims paperwork needs to be accounted for. This cost should be included only if it falls outside the job description, results in overtime, or is performed by a third party.

\section{Interest paid on delayed insurance claims compensation}

Interest paid on delayed insurance claims compensation refers to the interest lost due to expenditure incurred by the company for which it will be remunerated later. (Blumenstein et al., 2011).

\section{Security}

This item refers to the cost of additional security required due to an incident. Security costs should be included only if the incident required an increased level of security for a certain time period (e.g. the company needed 10 more security guards for a week while the incident was being investigated). If, however, security staff assist with an incident that leads to a security breach such as theft, this could result in an additional cost. If this temporary breach does lead to some form of criminal activity, the cost can also be indirectly attributed to the incident, since if the incident had not occurred, the theft would not have taken place.

\section{Work in progress}

This cost item refers to the cost incurred due to work-in-progress (WIP) products being halted along the production line. It is not as applicable to the mining industry as it would be to other industries. However, this could become a cost factor when an incident leads to a stoppage, where ore flow is stopped while undergoing a process (or where ore/waste needs to be re-handled due to an incident).

\section{Demurrage}

Demurrage refers to the penalties payable for not receiving delivery of consumables on contract (Blumenstein et al., 2011). Supplier contracts will provide the ruling on demurrage. It should, however, be noted that this is not a common occurrence in the mining industry, as the contracts are set up in such a way as to avoid these penalties.

\section{Uncompensated medical expenses}

An uncompensated medical expense refers to the cost of medical expenses other than those included in insurance. Examples would be mine dispensary costs (lump sum costs) and nonemergency transportation to a medical provider (time- and unit-related costs). Which medical expenses are covered by worker's compensation, and those that are the responsibility of the company, needs to be investigated. The potential sub-factors that may arise through uncompensated medical expenses can be seen in Table VIII.

\section{Additional consultant fees}

Additional consultant fees refers to any additional work performed relating to an incident. This item should, however, be added only if it was not accounted for under any of the other cost items.

\section{Fluctuating operating expenses}

Fluctuating operating expenses refers to a change in the average operating expenses due to an incident. The terms 'cost' or 'loss' are avoided as this item will in most cases lead to the mine expending less than it would have at steady-state production. Thus this item applies only if there is a mine stoppage. The assumption is that, for the duration of the stoppage no employee can work overtime, bonuses for the month fall away (depending on bonus structure), and employees who fall ill and are unable to work during that time will not have a financial impact (will not be double-accounted for with a replacement worker). The calculation of this item should focus on all expenses not incurred due to the incident, and it should reflect as a positive value.

\section{Table VII}

\section{Potential sub-factors: Employee replacement and training}

\begin{tabular}{|c|c|}
\hline Sub-factor & Definition/example \\
\hline Costs to attracting candidates (advertisements, agencies, etc.) & The cost of a recruiting agency to place advertisements and attract potential candidates. \\
\hline Costs to select candidates & The cost of a recruiting agency conducting preliminary interviews for potential candidates. \\
\hline Costs for interviews & The time cost for company human resources (HR) to conduct final interviews. \\
\hline Costs for psychometric assessments & $\begin{array}{l}\text { The cost of an external contractor providing these tests, as well as interpreting the results and writing up } \\
\text { individual reports. }\end{array}$ \\
\hline Administrative, accounting, and legal costs & $\begin{array}{l}\text { The time cost of company HR, as well as the costs associated with signing new contracts (if the time falls } \\
\text { outside of normal duties). }\end{array}$ \\
\hline Travel and lodging expenses & $\begin{array}{l}\text { The cost to company of providing allowance for travel and lodging while the candidate is going through } \\
\text { the selection process. }\end{array}$ \\
\hline Costs for medical examinations & $\begin{array}{l}\text { The cost of necessary medical examinations in order for the candidate to be declared medically fit to perform } \\
\text { the specific job. }\end{array}$ \\
\hline Training costs & The additional costs associated with training a new employee (mostly time-based costs). \\
\hline Other employees' time for on-the-job training & The additional cost incurred in training more employees than is the norm. \\
\hline Pay during training & $\begin{array}{l}\text { The cost associated with the company paying salary in full, even when the employee is not working and } \\
\text { busy with training. }\end{array}$ \\
\hline Training of temporary and replacement personnel & $\begin{array}{l}\text { Costs associated with training an existing employee to do other work until a new employee has } \\
\text { been assigned and trained. }\end{array}$ \\
\hline Costs for the team of integrating a new member & The loss in productivity when introducing a new member to a team (mostly due to on-the-job training). \\
\hline
\end{tabular}




\section{Identification of cost factors relating to mining incidents}

\section{Table VIII}

\section{Potential sub-factors: Uncompensated medical expenses}

\begin{tabular}{|l|l|}
\hline Sub-factor & Definition/example \\
\hline Medical bills/health care professional & $\begin{array}{l}\text { Additional treatment required for an injured employee, outside of the scope of normal, on-site treatment (physician, } \\
\text { specialist doctor, etc.). This can also include follow-up consultations with specialists. }\end{array}$ \\
\hline Medical treatment supplies & Consumption of medical supplies not provided on-site. \\
\hline Drug testing & Additional fees for drug testing due to incident (special tests) or fees for off-site testing. \\
\hline Medical equipment that is unusable after treatment & $\begin{array}{l}\text { If an injured employee needs immediate medical treatment which requires equipment and the equipment cannot be used } \\
\text { again (due to health and safety reasons). }\end{array}$ \\
\hline
\end{tabular}

This item is not really a cost item at all. The approach is to look at what the mine would have spent if no stoppage had occurred. Consumables are not consumed, electricity consumption goes down, etc. Thus this means that the mine is spending less during the stoppage than it would have while producing.

\section{Conclusions}

The identification and understanding of all cost factors relating to mine incidents proved to be more complex than expected. A number of objectives were reached through this study, and the following lessons learnt.

- In general, cost factors relating to workplace incidents can vary greatly. This is due to the difference in workplace environments across different industries. Another factor that plays a role in the cost factors relating to workplace incidents is the specific country where the incident occurred. Different policies around the world lead to different employer responsibilities in terms of the financial impact of incidents.

> The same can be concluded when narrowing down 'workplace incidents' to 'mining incidents'. Nevertheless, this study focused on identifying and understanding any potential cost factors relating to mine incidents, and these factors remained constant (regardless of the country of occurrence). Although the eventual financial impact felt by the employer would be country-specific, the potential factors remained the same.

- A list of 34 main factors relating to mine incidents, as well as numerous sub-factors, was compiled. From this list of potential factors it can be concluded that mine incidents can comprise a vast number of cost-contributing factors.

> These factors can also be very different in nature. Some may be incurred instantaneously, and others may only be realized long after the incident occurred.

In conclusion, the identification of any cost factors relating to mine incidents can be valuable to mining companies. If companies are aware of and understand which factors could contribute to the cost of any given incident, future planning and incident cost estimations will be easier. It should, however, be noted that although this study provides a comprehensive list of cost factors (and detailed explanations), other unknown cost factors relating to mine incidents could prevail in extreme case.

\section{Recommendations and suggestions for future work}

It is recommended that the work done in this specific study be used by mining companies to enhance understanding in the field of incident costs. Mine management and safety officers can benefit from the information presented, as it can provide a sound base for the on-site estimation of the cost of mining incidents.
It is further recommended that if the work in this study is to be used, the cost factors identified should be reviewed for the intended application, and sound judgment should be applied when assessing the applicability of factors to specific incidents.

It is suggested that further investigations be conducted into three of the identified cost factors. These three factors are:

> The financial impact of implementing job accommodations and/or work process modifications following an incident

> The financial impact of harm caused to a company's reputation following an incident

> The financial impact of decreased worker productivity caused by decreased morale, as well as the relationships between productivity, safety, and worker morale.

The abovementioned factors each lend themselves to highly detailed investigations, and it is suggested that each of these immeasurable factors be investigated in isolation.

\section{References}

ACE Group. 2013. Reputation at Risk. ACE European risk briefing 2013. http:// www.acegroup.com/global-assets/documents/Europe-Corporate/ThoughtLeadership/ace_reputation_at_risk_july_2013.pdf [accessed 12 September 2014].

AVMA PLIT. 2008. Direct versus indirect costs of injuries on the job at your practice. http://www.avmaplit.com/uploadedFiles/AVMAPLIT/Publications/Safety_and_ Loss_Control/664-Direct\%2520and\%2520Indirect $\% 2520$ Costs\%2520of\%2520I njuries.pdf [accessed 15 April 2014].

Behm, M. 2009. Employee morale - Examining the link to occupational safety and health. Journal of the American Society of Safety Engineers, October 2009. pp. 42-49.

Blumenstein, D.. Ferriter, R., Powers, J., and Reiher, M. 2011. Accidents - The total cost: A guide for estimating the total cost of accidents. Colorado School of Mines.

British Health and Safety Executive. 1998. Managing health and safety: Five steps to success. http://www.citb.co.uk/documents/awards [accessed 18 February 2014].

Gagne, R. 2011. What does a workplace injury cost? Direct versus indirect costs and their affect to the bottom line. Fit2Work, Melbourne.

Huang, Y., Leamon, T.B., Courtney, T.K., DeArmond, S., Chen, P.Y., and Blair, M.F. 2009. Financial decision makers' views on safety. Journal of the American Society of Safety Engineers, April 2011, pp. 36-42.

LaBelle, J. 2000. What do accidents truly cost? - Determining total incident costs. Journal of the American Society of Safety Engineers, April 2000. pp. 38-42.

Lebeau, M., Duguay, P., and Boucher, A. 2013. Estimating the costs of occupational injuries: A feasibility study in the mining industry. Institut de Recherche Robert-Sauvé en Santé et en Sécurité du Travail (IRSST), Montreal, Quebec.

Malaysian Department of Occupational Health and Safety. Not dated. Occupational safety $\&$ health accident cost calculator (OSHACC). http://www.dosh.gov.my/e apps/oshacc/oshacc_model_acc_cost.pdf [accessed 20 March 2014].

Manuele, F. 2011. Accident costs: Rethinking ratios of indirect to direct costs. Journal of the American Society of Safety Engineers, January 2011. pp. 39-47.

Royal Borough of Kensington and Chelsea. 2002. Reduce risks - Cut costs: The real cost of accidents and ill health at work. http://www.rbkc.gov.uk/pdf/ Reduce $\% 20$ risks\%20and\%20cut\%20costs\%20in\%20the\%20workplace.pdf [accessed 20 February 2014].

US Department of Labor. 2011. Background of cost estimates. http://www.osha.gov/ dcsp/smallbusiness/safetypays/background.html [accessed 18 April 2014].

Workers Compensation Board of British Columbia. Not dated. Small business safety calculator. http://www2.worksafebc.com/calculator/Calculator_worksheet.pdf [accessed 21 March 2014]. 